Abstract

\title{
The Effect of Micromixer Geometry on the Diameters of Emulsion Droplets: NIR Spectroscopy and Artificial Neural Networks Modeling ${ }^{\dagger}$
}

\author{
Tamara Jurina *, Ivana Čulo, Maja Benković, Jasenka Gajdoš Kljusurić, Davor Valinger and Ana Jurinjak Tušek

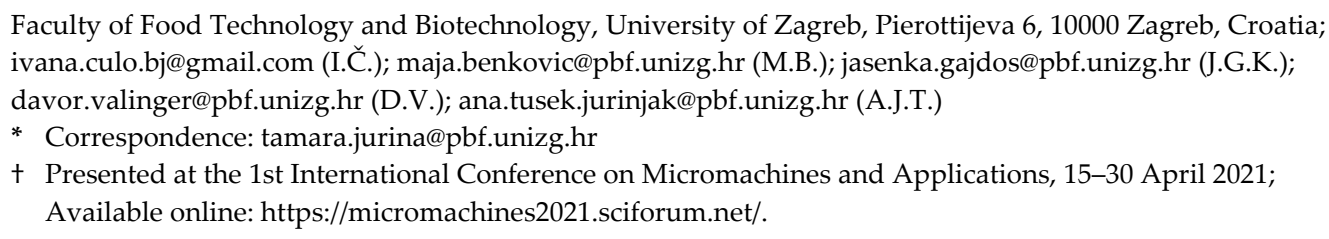
ivana.culo.bj@gmail.com (I.Č.); maja.benkovic@pbf.unizg.hr (M.B.); jasenka.gajdos@pbf.unizg.hr (J.G.K.); davor.valinger@pbf.unizg.hr (D.V.); ana.tusek.jurinjak@pbf.unizg.hr (A.J.T.)

* Correspondence: tamara.jurina@pbf.unizg.hr

† Presented at the 1st International Conference on Micromachines and Applications, 15-30 April 2021; Available online: https://micromachines2021.sciforum.net/.

Citation: Jurina, T.; Čulo, I.; Benković, M.; Kljusurić, J.G. Valinger, D.; Tušek, A.J. The Effect of Micromixer Geometry on the Diameters of Emulsion Droplets: NIR Spectroscopy and Artificial Neural Networks Modeling. Eng. Proc. 2021, 4, 26. https://doi.org/ 10.3390/Micromachines2021-09658

Academic Editor: Ion Stiharu

Published: 27 April 2021

Publisher's Note: MDPI stays neutral with regard to jurisdictional claims in published maps and institutional affiliations.

Copyright: $\left(C^{2} 221\right.$ by the authors. Licensee MDPI, Basel, Switzerland. This article is an open access article distributed under the terms and conditions of the Creative Commons Attribution (CC BY) license (http://creativecommons.org/licenses/by/4.0/).

\begin{abstract}
In this work, teardrop micromixer and swirl micromixer were used for preparation of oilin-water (O/W) emulsions with Tween 20 and PEG 2000 as emulsifiers (concentrations: 2\% and 4\%) at different total flow rates $(20-280 \mu \mathrm{L} / \mathrm{min})$. Stability of the prepared O/W emulsions was evaluated based on the droplet size of the dispersed phase. For determination of the droplet size, the average Feret diameter was used. Furthermore, near infrared (NIR) spectra of all prepared samples were collected. Obtained results showed that the change in the droplet size followed the same trend for both micromixers used in the experiment. At higher total flow rates, emulsification resulted in smaller values of the average Feret diameter. Values of the average Feret diameter were higher for emulsions prepared in the swirl micromixer, compared to the teardrop micromixer. Artificial Neural Network (ANNs) models, based on the recorded NIR spectra of emulsions, were developed to predict the droplet size of the dispersed phase. The obtained ANN models have high values of $R^{2}$ for training, test, and validation, with small error values and show that NIR spectroscopy, in combination with ANNs, could be efficiently used for evaluation of the stability of oil-in-water emulsions.
\end{abstract}

Keywords: micromixer geometry; average feret diameter; oil in water emulsions; artificial neural network models; NIR spectra

Supplementary Materials: The supplementary file is available at https://www.mdpi.com/article/10.3390/Micromachines2021-09658/s1.

Institutional Review Board Statement: Not applicable.

Informed Consent Statement: Not applicable.

Data Availability Statement: Not applicable. 